\title{
EXPOSICIÓN IMPRUDENTE AL DAÑO. TRANSMISIBILIDAD A LOS HEREDEROS. OPONIBILIDAD DE LA CULPA DE LA VÍCTIMA A LAS VÍCTIMAS POR REPERCUSIÓN O REBOTE
}

RECKLESS EXPOSURE TO DAMAGE. TRANSMISSIBILITY TO THE HEIRS. ENFORCEABILITY OF THE VICTIM'S OWN FAULT TO THE INDIRECT REBOUND VICTIMS

RAMÓN DOMÍNGUEZ AGUILA*

\section{RESUMEN}

El autor describe y analiza jurisprudencia reciente de la Corte Suprema que aborda el problema de la exposición imprudente al daño y su alegación en contra de los herederos de la víctima, revisa el parecer de la doctrina nacional en la materia, y exponiendo su posición, la posición mayoritaria de la doctrina y de la jurisprudencia, en orden a reconocer que la exposición imprudente al daño o "culpa de la víctima" es oponible a los herederos de la víctima, y por tanto la sentencia comentada hace correcta aplicación del artículo 2330 del Código Civil.

Palabras Clave: Responsabilidad civil, Culpa de la víctima, Exposición imprudente al daño, Causalidad, Transmisibilidad a herederos, Jurisprudencia de tribunales superiores, Derecho civil.

\footnotetext{
*Abogado. Licenciado en Ciencias Jurídicas y Sociales, Universidad de Concepción. Doctor en Derecho, Universidad de Toulouse, Francia. Profesor de Derecho Civil, Universidad de Concepción, Concepción, Chile. Correo: rda@entelchile.net. ORCID: https://orcid.org/0000-0001-7470-739X.
}

Trabajo recibido el 15 de diciembre de 2021, y aceptado para su publicación el 29 de diciembre de 2021. 


\section{ABSTRACT}

The author describes and analyzes recent cases of the Chilean's Supreme Court of Justice, and exposes about the reckless exposure to damage of a victim and his transmissibility to the heirs, reviewing the trends of his own opinion, the national doctrine and case law on this subject, and accepting as correct the opinion which recognizes that the reckless exposure to damage of a victim - victim's own fault - is enforceable to the victim's heirs, and therefore the commented sentence applies correctly the article 2330 of the Chilean Civil Code.

Keywords: Civil liability, victim's own fault, reckless exposure to damage, causation, Transmissibility to the heirs, Supreme Courts Jurisprudence, Civil law.

\section{DOCTRINA}

La reducción de la indemnización impuesta por el artículo 2330 del Código Civil resulta transmisible a los herederos de la víctima directa, toda vez que, si bien ese artículo supone que quien se exponga imprudentemente al daño sea quien también finalmente lo soporte, sin embargo habiendo deducido la acción los herederos de esa víctima como víctimas por repercusión o indirectas, no resulta sostenible que ellos queden en una posición más favorable de la persona de quien derivan los derechos que hacen valer. No parece justo que para invocar su pretensión el causahabiente haga valer el lazo que lo une con la víctima, y en cambio pretenda ser un extraño cuando se alegue que el accidente del que derivan los perjuicios, se debió en parte al hecho culpable de quien falleció. La víctima, de haber sobrevivido, no habría podido desligarse de su propia culpa para pretender una reparación integral, de manera que los causahabientes no pueden pretender que esa culpa no les sea opuesto porque es der la víctima directa que les viene el derecho. De lo contrario resultaría que al demandar a título personal el causahabiente tendría más derechos que la propia víctima.

Sentencia de la Corte Suprema, 19 de julio 2021, Rol 95.054-2020. 


\section{II.COMENTARIO}

La doctrina transcrita viene siendo admitida por la Corte Suprema desde algún tiempo. Así, la propia sentencia cita las de Corte Suprema de 19 de octubre 1981, en causa Rol 4735; de 25 de octubre de 1979, en causa Rol 2945; de 15 de diciembre del año 2009, en causa Rol 3345-2008 y agrega las sentencias de los roles 22.632-2014 y 6887-2015. A ellas agregamos por nuestra parte la sentencia del mismo tribunal de 10 de diciembre de 2015, autos Rol 25.380-2014, y la de la Corte de Valparaíso, de 10 de abril de 2017, en autos Rol civil 1077-2016.

De acuerdo a ella, la norma del artículo 2330 del Código Civil que manda reducir la indemnización de perjuicios extracontractual si la víctima se expuso imprudentemente al daño, es también aplicable al caso en que quienes deduzcan acción de indemnización de perjuicios sean los causahabientes de la víctima directa, no obstante que éstos no intervinieron en la causación del daño.

Esa doctrina no fue la tradicional en nuestro derecho. En efecto, don Arturo Alessandri Rodríguez en su clásica obra sobre responsabilidad extracontractual sostenía que cuando los causahabientes de la víctima directa deducían la acción indemnizatoria había que distinguir si lo hacían como herederos de ésta, caso en el cual sin duda se les aplicaba el artículo 2330 del Código Civil, porque los herederos representan a la persona de víctima directa y por ende no pueden tener más derechos que ésta. "Pero si actúan en su propio nombre, en razón del daño personal que sufren al verse privados de los recursos que la víctima directa les daba o a consecuencias del dolor que les produce la muerte de ésta o la lesión inferida a ella o por los gastos en que han incurrido con motivo del accidente, ese precepto es inaplicable: el que sufre el daño de cuya indemnización se trata no se expuso a él imprudentemente". ${ }^{1}$

Aunque con matices, semejante solución es acogida por Pablo RODRÍGUEZ GREZ. ${ }^{2}$

Sin embargo, la posición acogida en la sentencia que se comenta es la aceptada por otros autores. Así, el profesor Enrique BARROS BOURIE escribe,

\footnotetext{
${ }^{1}$ Alessandri Rodríguez, Arturo, De la Responsabilidad Extracontractual en el Derecho Civil Chileno, Imprenta Universitaria, Santiago, 1943, n 481.

${ }^{2}$ Rodríguez Grez, Pablo, Responsabilidad Extracontractual, Editorial Jurídica, Santiago, 1989, p. 354.
} 
a propósito de la distinción hecha por Alessandri y ya referida, que

"La distinción parece por completo artificiosa, porque aun si la acción por daño de rebote es ejercida a título personal, la responsabilidad de quien ha participado en el accidente debe ser medida en relación con la conducta de la víctima. Lo contrario sería injusto respecto del demandado, porque como se ha visto, el instituto de la culpa de la víctima atiende a la relación a la conducta del demandado que ha actuado con culpa y la conducta de la víctima. Por eso es absurdo que el demandado no disponga contra la víctima de rebote de una excepción que dispondría contra la víctima directa que sobreviva al accidente. La doctrina y la jurisprudencia tienden a converger en esta solución". ${ }^{3}$

Por nuestra parte, en el primer artículo que escribí, hace ya más de cincuenta años, ${ }^{4}$ sostuve la tesis de la sentencia que se comenta. Indicando que no es posible sostener una supuesta independencia entre los daños sufridos por la víctima directa y los que soportan sus herederos, por cuanto éstos sólo invocando los vínculos que los unen a esa víctima pueden pretender una acción reparadora de sus propios perjuicios, no siendo equitativo que, para invocar el derecho a demandar una reparación se haga valer el vínculo que los une a la víctima y que pretendan ser terceros extraños cuando se alega que el accidente se ha debido en parte al hecho culpable de esa víctima directa. ${ }^{5}$ El lazo es indisoluble, ya que es el que justifica la acción y el hecho originario de todos los perjuicios es el mismo. Si se siguiera la posición de AlESSANDRI, los causahabientes, como lo señala acertadamente la sentencia que se comenta, resultarían tener más derechos que los de la víctima directa, lo que resulta en un absurdo. En comentario de sentencia en la misma Revista, años más tarde insistí en la materia. ${ }^{6}$

\footnotetext{
${ }^{3}$ Barros Bourie, Enrique, Tratado de Responsabilidad Extracontractual, Editorial Jurídica, Santiago 2020, 2a . edición, T. I, n 291.

${ }^{4}$ Domínguez Águila, Ramón, "El Hecho de la Victima como causal de exoneración de responsabilidad civil”, Revista de Derecho Universidad de Concepción, 1966, № 136, pp. 29-54.

${ }^{5}$ Domínguez Águila, cit. (n. 4), p. 52.

${ }^{6}$ Domínguez Águila, Ramón, “Comentarios de Jurisprudencia. Inaplicabilidad de la responsabilidad subsidiaria laboral en la acción extracontractual civil. Inoponibilidad de la culpa de la víctima a las
} 
La profesora Lilian SAN MARTín ha recogido en una excelente monografía los argumentos de la tesis de la oponibilidad de la culpa de la víctima a los causahabientes de la víctima directa, adhiriendo a ellos. ${ }^{7}$

La cuestión se ha discutido desde antiguo en el derecho francés; ${ }^{8}$ pero la jurisprudencia se ha inclinado sin duda por la oponibilidad de la culpa de la víctima directa a sus herederos. Ha sido decisiva así la sentencia de las Cámaras Reunidas de la Corte de Casación francesa de 25 de noviembre de $1964^{9} \mathrm{y}$, ante ciertas disidencias, por último la oponibilidad fue confirmada por la sentencia de la Asamblea Plenaria de la Corte de Casación de 19 de junio de $1981^{10}$ en dos pronunciamientos.

La solución es aceptada por la doctrina actual, bajo la base siguiente: "para ser perjudicado por una persona diferente, el perjuicio por rebote no deja de proceder del mismo hecho generador que el perjuicio de la víctima inmediata" ${ }^{11}$ Y ha sido consagrada en materia de accidentes de la circulación (L. 85-677, art. 6). De acuerdo a dicha norma "lo que es oponible a las víctimas por repercusión es, ni más ni menos, lo que es o lo ha sido oponible a la víctima directa". ${ }^{12}$

En el derecho alemán, el artículo 846 del $B G B$ hace expresamente oponible a la víctima indirecta la culpa de la víctima directa. La misma doctrina se sigue en el derecho norteamericano. ${ }^{13}$

La solución de la sentencia comentada es así inobjetable.

víctimas por repercusión o rebote", Revista de Derecho Universidad de Concepción, 2004, n² 215-216, pp. 357-362 (comentario crítico a sentencia de la Corte de Apelaciones de Concepción, 2 de noviembre de 2005, Rol civil 2269-2005).

${ }^{7}$ San Martín NeIra, Lilian, La culpa de la víctima en la responsabilidad civil, DER, Santiago, 2018, pp. 159 ss.

${ }^{8}$ Sobren ello, vid. VIneY, Geneviève; JourdaIn, Patrice, Les Conditions de la Responsabilité, L.G.D.J., Paris, 2006, 3a. edic., $\mathrm{n}^{\circ} 435$ y ss.

${ }^{9}$ Ch. Réunies, 25 noviembre 1964, D. 1964, p. 733, conclusiones de Aydalot; J.C.P. 1964, II, 13972, nota de P. Esmein; Rev. Trim. Dr. Civ. 1964, p. 136, obs. René Rodiére.

${ }^{10}$ Cass. Ass. Plénière, 19 de junio 1981, J.C.P. 1982, rapp. Ponsard; D. 1982. 85, conclusiones de Cabannes y nota de F. Chabas.

${ }^{11}$ Le Tourneau, Philippe (dir.), Droit de la Responsabilité et des Contrats. Régime d indemnisation, Dalloz, Paris, 2014, $10^{\circ}$ edición, $\mathrm{n}^{\circ} 995$.

${ }^{12}$ ChabAs, Francoise, "L' interprertation des articles 2 à 6 de la loi du 5 juillet 1985 et la question des recours", Gazzete du Palais 1995. 1, doctrina, p. 656.

${ }^{13}$ Así: Prosser, William L.; Keeton, Page, Prosser and Keeton on Torts, West Publishing Co., St. Paul, 1984, 5a ed., p. 954 y las sentencias citadas en nota 9. 
La solución contraria desconoce por lo demás, fuera de los argumentos ya referidos, el análisis del elemento causal. El fundamento del artículo 2330 ha de encontrarse en el análisis de la relación de causalidad. ${ }^{14}$ Es porque la víctima directa ha contribuido con su hecho culpable a la producción de su daño que la indemnización debe ser rebajada en proporción a la eficacia causal de ese hecho. Su daño tiene así dos causas concurrentes. Como el daño indirecto de los causahabientes está en íntima relación con el daño a la víctima directa, tiene el mismo origen causal y, por tanto, la culpa de la víctima directa es también concausa de ese daño por rebote o por repercusión. ${ }^{15}$ Como dice la sentencia de la Asamblea Plenaria de la Corte de Casación francesa ya referida, "si la acción del tercero es distinta por su objeto (incluso si este tercero es también heredero de la víctima) de aquella que la víctima habría podido ejercer, ella no deja de proceder del mismo hecho originario considerado en todas sus circunstancias".

La sentencia comentada, insistiendo en una doctrina ya aceptada por otras anteriores, nos parece que debe poner término a la cuestión, estableciendo en modo definitivo la oponibilidad de la culpa de la víctima a las víctimas por repercusión o rebote.

\footnotetext{
${ }^{14}$ Sobre ese fundamento en la división de responsabilidades entre el hechor y la víctima directa en caso de culpas concurrentes, véase: Medina Alcoz, María, La Culpa de la Victima en la producción del daño extracontractual, Dykinson, Madrid, 2003, pp. 214 y ss.

${ }^{15}$ Por la íntima relación existente entre la acción de la víctima directa y la acción de las víctimas por repercusión se justifica la oponibilidad de la culpa de la primera a los causahabientes de ella. Sobre ello, entre nosotros, KUNCAR, Andrés, “¿Es el estatuto de la responsabilidad extracontractual aplicable a las víctimas por repercusión o rebote?”, en Elorriaga, F. (coord.), Estudios de Derecho Civil VII, Abeledo Perrot, Thomson Reuters, Santiago, 2012, p. 705.
} 


\section{BIBLIOGRAFÍA CITADA}

\section{a) Doctrina}

Alessandri Rodríguez, Arturo, De la Responsabilidad Extracontractual en el Derecho Civil Chileno, Imprenta Universitaria, Santiago, 1943, n 481.

Barros Bourie, Enrique, Tratado de Responsabilidad Extracontractual, Editorial Jurídica de Chile, Santiago, 2020, $2^{\mathrm{a}}$ edición, T. I.

Chabas, Francoise, "L'interpretation des articles 2 à 6 de la loi du 5 juillet 1985 et la question des recours", Gazzete du Palais, 1995. 1, doctrina.

Domínguez Águila, Ramón, "El Hecho de la Victima como causal de exoneración de responsabilidad civil", Revista de Derecho Universidad de Concepción, 1966, $\mathrm{N}^{\circ} 136$, pp. 29-54.

Domínguez ÁGuILA, Ramón, “Comentarios de Jurisprudencia. Inaplicabilidad de la responsabilidad subsidiaria laboral en la acción extracontractual civil. Inoponibilidad de la culpa de la víctima a las víctimas por repercusión o rebote", Revista de Derecho Universidad de Concepción, 2004, n²15-216, pp. 357-362.

KunCAR, Andrés, "¿Es el estatuto de la responsabilidad extracontractual aplicable a las víctimas por repercusión o rebote?", en ElorRIAGA, F. (coord.), Estudios de Derecho Civil VII, Abeledo Perrot, Thomson Reuters, Santiago, 2012.

Le Tourneau, Philippe (dir.), Droit de la Responsabilité et des Contrats. Régime d indemnisation, Dalloz, Paris, 2014, $10^{\circ}$ edición.

Medina Alcoz, María, La Culpa de la Víctima en la producción del daño extracontractual, Dykinson, Madrid, 2003.

Prosser, William L.; Keeton, Page, Prosser and Keeton on Torts, West Publishing Co., St. Paul, 1984, 5a edición.

RodríGuez Grez, Pablo, Responsabilidad Extracontractual, Editorial Jurídica de Chile, Santiago, 1989.

SAN Martín NeIRA, Lilian, La culpa de la víctima en la responsabilidad civil, DER, Santiago, 2018.

Viney, Geneviève; Jourdain, Patrice, Les Conditions de la Responsabilité, L.G.D.J., Paris, 2006, 3a. edición.

b) Jurisprudencia

Corte de Apelaciones de Concepción, 2 de noviembre de 2005, Rol civil 2269-2005 2016.

Corte de Apelaciones de Valparaíso, 10 de abril de 2017, Rol civil 1077-

Corte Suprema, 10 de diciembre de 2015, Rol 25.380-2014.

Corte Suprema, 15 de diciembre del 2009, Rol 3345-2008.

Corte Suprema, 19 de julio 2021, Rol 95.054-2020.

Corte Suprema, 19 de octubre 1981, Rol 4735.

Corte Suprema, 23 de julio de 2015, Rol 22.632-2014.

Corte Suprema, 24 de noviembre de 2015, Rol 6887-2015.

Corte Suprema, 25 de octubre de 1979, Rol 2945. 